\title{
Zinc Deficiency Acts as a Co-Teratogen with Alcohol in Fetal Alcohol Syndrome
}

\author{
LAURA DAVIS KEPPEN, THEODORE PYSHER, AND OWEN M. RENNERT
}

Department of Pediatrics [L. D. K.J, University of Arkansas for Medical Sciences, Little Rock, Arkansas 72205 and Departments of Pediatrics [O. M. R.] and Pathology /T. P.], University of Oklahoma Health Sciences Center, Oklahoma, City, Oklahoma 73190

\begin{abstract}
Because alcoholism has adverse effects on zinc nutrition and many pregnant women consume less than the recommended dietary allowances of zinc, we postulated that zinc deficiency acts as a co-teratogen with alcohol in the fetal alcohol syndrome. We compared the effects of alcohol on progeny of pregnant mice fed a zinc-deficient diet compared to those fed a diet with adequate zinc. Pregnant CBA mice $(n=66)$ were fed the Lieber-DeCarli liquid diet with 0,15 , or $20 \%$ ethanol-derived calories containing 0.3 (low) or 8.5 (high) $\mu \mathrm{g}$ zinc/ml. Dams were sacrificed on day 18 of gestation. Resorptions, malformations, and individual fetal weights were recorded. Analysis of fetuses included assays for zinc, assessment of soft tissue malformations, and alizarin red staining for skeletal malformations. Fetal weights were lower in the groups fed the zinc-deficient diet for each concentration of alcohol $(p<$ 0.005 ). The groups fed the combination of low zinc plus alcohol had $37-52 \%$ resorptions, while the animals on the zinc-deficient diet without alcohol or the high zinc diet with alcohol had $0-2 \%$ resorptions. Skeletal malformations were related to alcohol concentration but not zinc intake, while external malformations were higher in those maintained on the low zinc-ethanol diet. These results suggest that zinc deficiency potentiated the teratogenic effects of alcohol and that nutritional intervention for alcoholic women during pregnancy might reduce the incidence or severity of fetal alcohol syndrome. (Pediatr Res 19: 944-947, 1985)
\end{abstract}

Abbreviation

ETOH, ethanol

Since Jones et al. (1) described a distinctive pattern of anomalies in children of alcoholic mothers termed the fetal alcohol syndrome, many investigators have attempted to characterize the mechanism of the teratogenic effects of alcohol. The fetal alcohol syndrome may be the third leading cause of mental retardation (2) with a frequency of between one in 600 and one in 1000 births in the US (3), but the teratogenic mechanism of alcohol is unknown.

The demonstration of Flynn et al. (4) that alcoholic women had significantly lower plasma zinc levels than nonalcoholic women stimulated interest in the etiologic role of zinc deficiency in the fetal alcohol syndrome. Maternal zinc deficiency is known to be teratogenic, and investigators have noted a similarity be-

Received October 18, 1984: accepted April 10, 1985.

Address reprint requests to Laura Davis Keppen, M.D., Department of Pediatrics, University of Arkansas for Medical Sciences, 4301 West Markham, Little Rock. AR 72205. tween the congenital malformations noted in the fetal alcohol syndrome and those produced by zinc deficiency $(5,6)$. Alcohol is known to have an adverse effect on zinc nutrition, with hypozincemia and increased urinary losses of zinc noted in alcoholic patients (5). Alcohol interferes with placental transport of zinc (7), which may explain the growth retardation associated with the fetal alcohol syndrome (8). In addition, dietary zinc intake averages considerably less than the recommended daily allowance in middle and low income groups (9). Malnutrition is more common among alcoholic individuals (10), so it is likely that their zinc intake is even lower.

Animal models of the fetal alcohol syndrome have attempted to eliminate nutritional variables (11) and have demonstrated teratogenic effects of alcohol in well-nourished animals (12-15). Zinc deficiency increases the susceptibility of the fetus to teratogens in rats given thalidomide (16), and it is possible that zinc deficiency augments the teratogenic effects of alcohol.

The present investigation was designed to compare the effects on the fetus of maternal ingestion of alcohol with a zinc deficient diet compared to alcohol ingestion with high zinc intake or a zinc-deficient diet without alcohol in a mouse model of the fetal alcohol syndrome. Specific aspects investigated were fetal resorptions, weight, malformations, and tissue zinc concentrations.

\section{MATERIALS AND METHODS}

Subjects. Virgin CBA/J females purchased from the Jackson Laboratory, Bar Harbor, ME, were maintained on a 12-h lightdark cycle and had free access to dry food and tap water. In preparation for breeding they were housed seven to eight per cage for 3 days. Females ages 64-79 days were placed with fertile $\mathrm{CBA} / \mathrm{J}$ males and examined every $24 \mathrm{~h}$ at $0800-0900 \mathrm{~h}$ for the presence of vaginal plugs. The presence of a vaginal plug was designated as day 1 of gestation. Each pregnant female was randomly assigned to one of the treatment groups and then individually housed in a stainless steel cage.

Diet and composition. Liquid diets of the Lieber-DeCarli formulation for pregnant mice were obtained from Bio-Serv, Frenchtown, NJ, (Bio-Mix nos. 1395, 0835, 1411, 1412). These six liquid diets provided the sole source of liquid and calories and were identical except for zinc and alcohol content. The high zinc groups received $8.5 \mu \mathrm{g} \mathrm{zinc} / \mathrm{ml}$, which is the amount recommended for reproduction (17); while the low zinc groups received $0.3 \mu \mathrm{g}$ zinc $/ \mathrm{ml}$. The average daily zinc consumption of the various dietary groups was as follows: high zinc groups, 182 $\mu \mathrm{g}$; low zinc groups, $7 \mu \mathrm{g}$. Alcohol groups received $15 \%$ or $20 \%$ of the calories as ETOH, while the 0\% ETOH groups received isocalorically balanced maltose-dextrin. The concentration of zinc in the diets was verified by flame atomic absorption spectroscopy. Animals received the liquid diets from inverted $50-\mathrm{ml}$ plastic syringes with rubber stoppers containing stainless steel ball point drinking tubes. To assess for possible zinc contami- 
nation via the feeding apparatus, zinc concentration of double deionized water and the various liquid diets was determined after storing the individual liquids for $5 \mathrm{~h}$ in the plastic syringes with rubber stoppers and then dripping the liquids through the feeding tubes. Zinc concentrations were not altered. Daily fluid consumption and caloric intake were determined daily by measuring the amount of fluid left each day between 0800 and $0900 \mathrm{~h}$.

Experimental design. The subjects in experiment 1 were given food and tap water ad libitum from gestational days 1-18, 20\% $\mathrm{ETOH} /$ high zinc liquid diet (no. 1395) ad libitum from gestational days $1-18$, or $0 \% /$ ETOH high zinc diet (no. 0835) from days $1-18$ restricted to the mean amount consumed the previous day by the alcohol group.

Because of the low number of dams with implantations in the alcohol group in experiment 1 , the subjects in experiment 2 received the liquid diet from gestational days 6-18 starting after the time of implantation. Rasmussun and Christensen (18) previously demonstrated that alcohol interferes with implantation. Groups in experiment 2 consisted of high zinc/15\% ETOH (no. 1395) ad libitum, low zinc/15\% ETOH (no. 1412) ad libitum, low zinc $/ 20 \%$ ETOH (no. 1412) ad libitum, and high zinc $0 \%$ ETOH (no. 1411) pair fed with the low zinc/ETOH groups. All liquid diets were refrigerated until used and discarded after $24 \mathrm{~h}$. Low zinc liquid diets were prepared with deionized water.

Animals were weighed on gestational days 1, 8, 15, and 18 . Prior to sacrifice on day 18 , blood was obtained by cardiac puncture for plasma alcohol concentrations, which were measured by gas chromatography (Shimadzu GC-3BF). The dams were sacrificed between 0900 and $1000 \mathrm{~h}$ on day 18 by cervical dislocation. The abdominal wall was immediately opened and the contents of the uterus were examined. Each resorption site or fetus was identified by the location in the uterus. Fetuses were weighed and then assigned randomly for zinc determinations or for morphologic studies. Morphologic studies consisted of freehand razor sectioning after fixation in Bouin solution or skeletal examination after staining with alizarin red S (19). Paraffin sections stained with hematoxylin and eosin were prepared from two animals from each dietary group after freehand sectioning of fetuses fixed in Bouin solution. Experimenters were blind to diet group at the time of sacrifice and later morphologic examination.

Fetuses assigned for zinc determinations were quick frozen in liquid nitrogen and then stored at $-70^{\circ} \mathrm{C}$. Zinc determinations were performed by atomic absorption spectrophotometry (model 251 . Instrumentation Laboratory, Lexington, MA) with a lean blue flame at $213.9 \mathrm{~nm}, 5 \mathrm{ma}$ current and slit width 320 after dry ashing as outlined by Clegg et al. (20).

Maternal livers were removed and divided. One portion was fixed in Bouin solution for sectioning and staining with hematoxylin and eosin; the remaining liver was quick frozen for zinc determinations as outlined above.

\section{RESULTS}

The combination of low zinc and ETOH had more severe effects on the fetus than either ETOH or low zinc alone. Resorption sites were high only in the low zinc/ethanol groups (Table 1). The groups fed the combination of low zinc plus ETOH had $37-52 \%$ resorptions, while the animals on the zinc deficient diet without alcohol or the high zinc diet with alcohol had $0-2 \%$ resorptions ( $p<0.01$ by $\chi^{2}$ test). Fetal weights were lower for each concentration of alcohol in the low zinc groups (two factor factorial analysis of variance using mean fetal weight per dam as the unit to control for effect of litter size on weight, $p<0.005$ ) (Fig. 1).

External malformations were most profound in the low zinc/ ETOH groups (Table 2). Open eyelids were a common external malformation. This defect has been described previously in the mouse model of fetal alcohol syndrome (12). Open eyelids were noted in approximately half the low zinc/ $0 \%$ ETOH and low
Table 1. Effect of diet on resorptions

\begin{tabular}{|c|c|c|c|c|}
\hline & Diet & $\begin{array}{c}\text { No. } \\
\text { of } \\
\text { litters }\end{array}$ & $\begin{array}{c}\text { No. of } \\
\text { implants }\end{array}$ & $\begin{array}{c}\text { No. } / \% \\
\text { resorptions }\end{array}$ \\
\hline \multirow[t]{3}{*}{ High zinc } & $0 \%$ ЕTOH & 5 & 23 & $0 / 0 \%$ \\
\hline & $15 \%$ ЕТОН & 8 & 56 & $1 / 2 \%$ \\
\hline & $20 \% \mathrm{ETOH}$ & 2 & 15 & $0 / 0 \%$ \\
\hline \multirow[t]{3}{*}{ Low zinc } & $0 \%$ ETOH & 4 & 26 & $0 / 0 \%$ \\
\hline & $15 \%$ ETOH & 8 & 56 & $21 / 37 \% *$ \\
\hline & $20 \% \mathrm{ETOH}$ & 4 & 27 & $14 / 52 \% *$ \\
\hline
\end{tabular}

* Significantly different by the $\chi^{2}$ test. $\chi^{2}=46.68, p<0.01$.

Effect of Diet on Fetal Weight

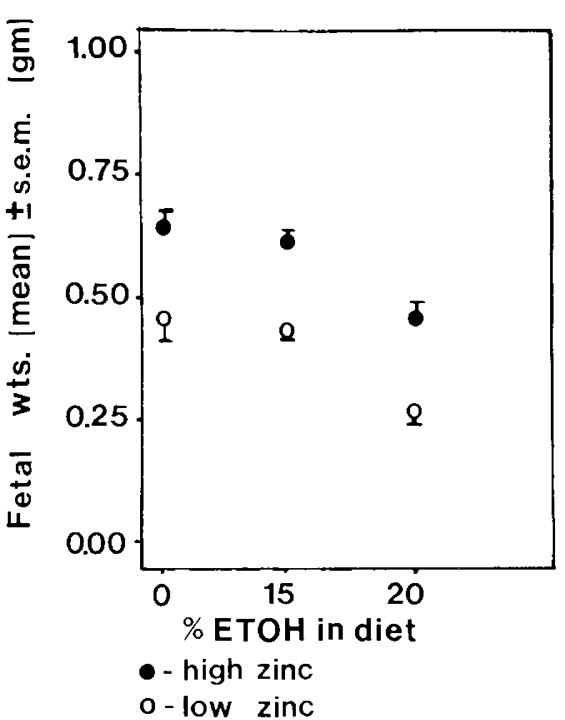

Fig. 1. Graph showing mean fetal weights in the high and low zinc groups for each concentration of ethanol. Two factor factorial analysis of variance, $p<0.005, F=48.5$ zinc effect; $p<0.01, F_{2}=29.7$ alcohol effect.

Table 2. Types and frequency of external malformations

\begin{tabular}{|c|c|c|c|c|c|}
\hline \multicolumn{2}{|c|}{ Diet } & \multirow{2}{*}{$\frac{n}{6}$} & \multirow{2}{*}{$\begin{array}{c}\text { Open } \\
\text { lids } \\
0\end{array}$} & \multirow{2}{*}{$\begin{array}{c}\text { Short } \\
\text { limbs } \\
0\end{array}$} & \multirow{2}{*}{$\begin{array}{c}\begin{array}{c}\% \\
\text { Abnormal }\end{array} \\
0\end{array}$} \\
\hline Mouse food & & & & & \\
\hline \multirow[t]{3}{*}{ High zinc } & $0 \%$ ЕTOH & 7 & 0 & 0 & 0 \\
\hline & $15 \% \mathrm{ETOH}$ & 15 & 1 & 0 & 7 \\
\hline & $20 \%$ ЕТOH & 4 & 1 & 0 & 25 \\
\hline \multirow[t]{3}{*}{ Low zinc } & $0 \%$ ETOH & 9 & 4 & 0 & $44^{*}$ \\
\hline & $15 \%$ ETOH & 9 & 5 & 4 & $56^{*}$ \\
\hline & $20 \% \mathrm{ETOH}$ & 7 & 7 & 6 & 100 \\
\hline
\end{tabular}

* Significantly different by the $\chi^{2}$ test. $\chi^{2}=17.5, p<0.01$

zinc/ $15 \%$ ETOH diet fetuses but occurred in all of the low zinc/ $20 \%$ ETOH fetuses. Developmentally retarded, immature-appearing fetuses with large heads and short extremities in proportion to body were noted only in the groups fed a zinc-deficient diet with alcohol (Fig. 2). Hydrocephalus, absent corpus callosum, cardiac anomalies, exencephaly, gastroschisis, limb defects, hydronephrosis, and hydroureter previously noted by Chernoff (12) and Randall et al. (14) in mice fetuses exposed to alcohol were not observed.

Histologic study showed that the lungs and kidneys of the low zinc plus ETOH groups appeared as mature or more so than those in the other groups, indicating that the smaller size of the fetuses in the low zinc plus ETOH groups cannot be attributed 


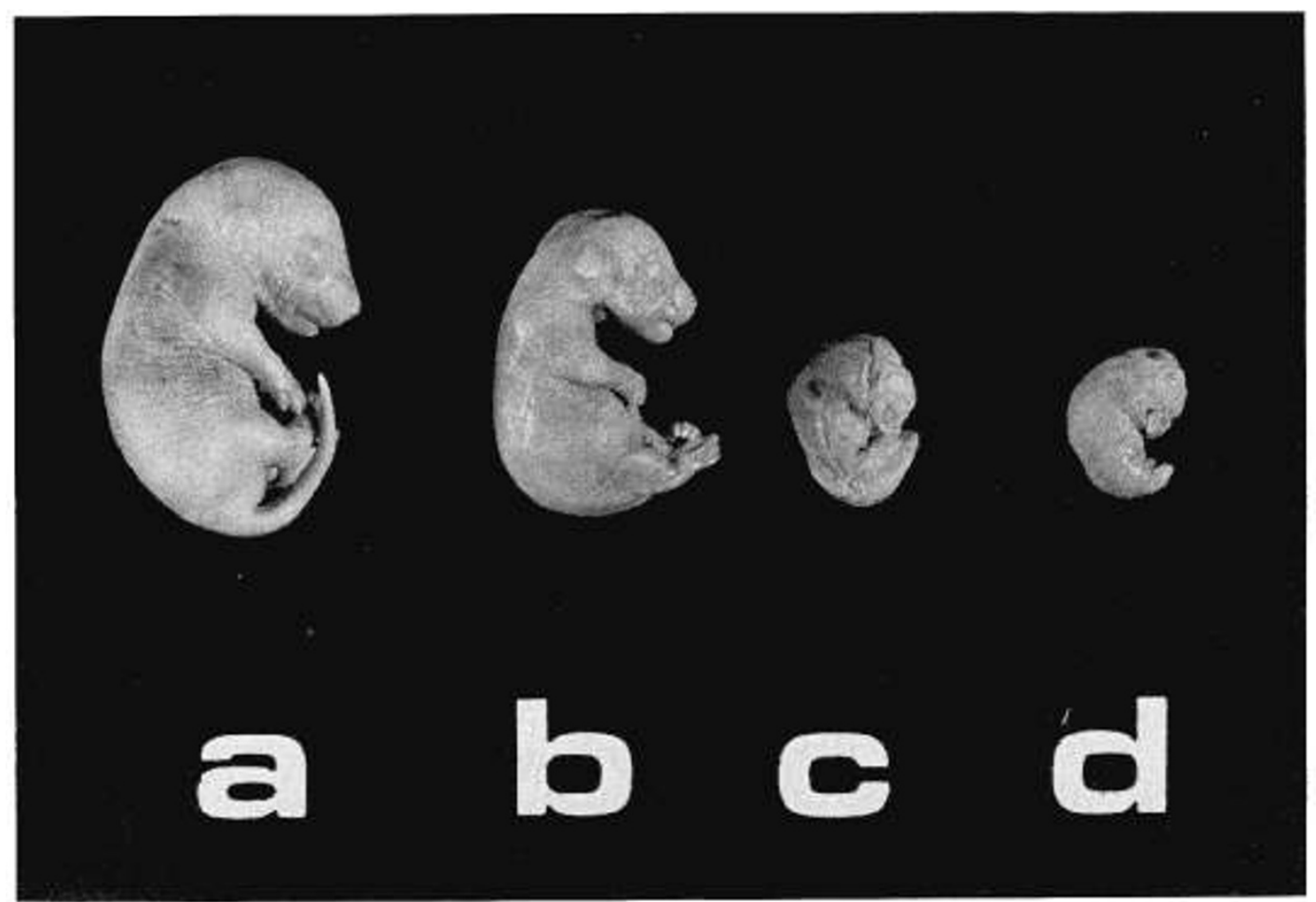

Fig. 2. Representative fetuses. $a$, high zinc $0 \%$ ETOH control; $b$, high zinc $20 \% \mathrm{ETOH}$; , low zinc $15 \% \mathrm{ETOH}$; $d$, low zinc $20 \% \mathrm{ETOH}$. Note that $c$ and $d$ are small, developmentally retarded fetuses with open eyelids.

Table 3. Effect of diet on zinc concentrations

\begin{tabular}{crcccc}
\hline \multirow{2}{*}{ Diet } & \multicolumn{3}{c}{ Zinc concentrations $(\mu \mathrm{g} / \mathrm{g}$ wet wt $)$} \\
\cline { 3 - 6 } & & $\begin{array}{c}\text { Fetus } \\
\text { (mean } \pm \mathrm{SD})\end{array}$ & $n$ & $\begin{array}{c}\text { Maternal liver } \\
(\text { mean } \pm \mathrm{SD})\end{array}$ & $n$ \\
\hline \multirow{3}{*}{ High zinc } & $0 \% \mathrm{ETOH}$ & $18.0 \pm 1.0$ & 4 & $45.0 \pm 14.9$ & 3 \\
& $15 \% \mathrm{ETOH}$ & $18.3 \pm 1.2$ & 7 & $42.8 \pm 9.5$ & 5 \\
& $20 \% \mathrm{ETOH}$ & $17.6 \pm 3.6$ & 3 & $30.3 \pm 3.7$ & 3 \\
Low zinc & $0 \% \mathrm{ETOH}$ & $15.7 \pm 2.4$ & 3 & $39.4 \pm 4.9$ & 4 \\
& $15 \% \mathrm{ETOH}$ & $17.7 \pm 3.0$ & 5 & $38.9 \pm 4.5$ & 6 \\
& $20 \% \mathrm{ETOH}$ & $15.6 \pm 2.0$ & 2 & $38.3 \pm 4.1$ & 4 \\
\hline
\end{tabular}

to a difference in gestational age. Organogenesis of cerebrum, cerebellum, heart, lung, liver, kidney, skeletal muscle, and vertebral bone appeared normal.

The only skeletal abnormality noted was decreased staining of the cranial bones (Fig. 3). This appeared to be related to alcohol but not zinc levels. This finding has been previously described as a feature of the fetal alcohol syndrome in mice (12).

Fetal zinc concentration did not vary significantly in the dietary groups (2 factor factorial analysis of variance) (Table 3 ). Fetal zinc content per uterus was lowest in the low zinc/ETOH groups due to lower fetal weights and high resorption rate.

The $12 \%$ rate of pregnancy observed in animals given the high zinc $20 \%$ ETOH diet from day 1 of gestation compared to pregnancy rates of $57-66 \%$ in the animals given the same calories from day 1 of gestation (high zinc $0 \% / \mathrm{ETOH}$ diet) or who received alcohol from day 6 after implantation (high zinc/15\% ETOH, low zinc/15\%, and $20 \%$ ETOH diets) indicates that alcohol interferes with implantation (Table 4). Maternal deaths occurred only in dams given alcohol, with the highest rate observed in the $20 \%$ alcohol groups. Dam plasma alcohol concentrations were widely variable, with levels from $0-311 \mathrm{mg} / \mathrm{dl}$. Many of the animals ingesting the ethanol diet had very low concentrations of blood alcohol, despite the observance of behavioral effects of alcohol such as tremor. The unexpectedly low blood alcohol concentrations are presumed to be related to the timing of blood drawing. Blood was drawn at the time of sacrifice at $0900-1100 \mathrm{~h}$, whereas mice ingested most of the diet at night.

All of the dams fed a zinc-deficient diet had clinical evidence of zinc deficiency, with skin lesions, alopecia, and diarrhea. Maternal liver zinc concentrations did not vary significantly among dietary groups ( 2 factor factorial analysis of variance) (Table 3). Microscopic examination of maternal livers revealed no steatosis or cirrhosis.

\section{DISCUSSION}

The results of this study suggest that the teratogenic effects of ETOH and low dietary zinc in combination are much greater than the effects of either alone. This is shown most dramatically by the resorption rate, which was high only in the groups given the low zinc diet with alcohol. Fetal weight reductions and external malformations were also more severe as a result of low zinc plus ETOH.

Ruth and Goldsmith (21) were the first to demonstrate that more pregnancy complications occurred in rats given a single intraperitoneal dose of ETOH during acute zinc deficiency. These experiments did not give alcohol orally. Miller et al. (22) showed that the combination of low doses of alcohol and marginal zinc deficiency during gestation resulted in increased external and internal defects in mouse fetuses.

In this study the effects of alcohol consumption were compared in groups given very low dietary zinc to those given the amount of zinc recommended during reproduction, with all other nutritional variables held constant. Alcohol interfered with implantation in the absence of zinc deficiency as was also noted by Rasmussen and Christensen (18). This could be a factor in the higher rate of spontaneous abortion observed among women who drink moderate to heavy amounts of alcohol during pregnancy (23).

Fetal zinc concentrations did not vary significantly with alcohol content of the diet, although total uterine zinc content decreased in the zinc deficient plus alcohol groups because of lower fetal weights. This suggests that the teratogenic effects were not the result of lower zinc concentrations in the fetus and that 
Table 4. Effect of diet on pregnancy rate, maternal deaths, caloric intake, and wt gain

\begin{tabular}{|c|c|c|c|c|c|c|}
\hline & & No. of dams & No. $/ \%$ Pregnant & No. $/ \%$ Deaths & $\begin{array}{c}\text { Mean daily } \\
\text { caloric intake } \\
(\text { kcal })\end{array}$ & $\begin{array}{c}\text { Mean wt gain } \\
(\mathrm{g})\end{array}$ \\
\hline \multirow[t]{3}{*}{ High zinc } & $0 \% \mathrm{ETOH}^{*}$ & 8 & $5 / 62$ & $0 / 0$ & $17.2 \pm 0.7$ & $3.9 \pm 0.7$ \\
\hline & $15 \% \mathrm{ETOH}$ & 12 & $8 / 66$ & $1 / 8$ & $26.1 \pm 1.8$ & $11.4 \pm 2.9$ \\
\hline & $20 \%$ ETOH $^{*}$ & 16 & $2 / 12$ & $1 / 19$ & $19.9 \pm 1.6$ & $10.6 \pm 2.3$ \\
\hline \multirow[t]{3}{*}{ Low zinc } & $0 \%$ ЕTOH & 7 & $4 / 57$ & $0 / 0$ & $20.6 \pm 0.9$ & $4.9 \pm 2.7$ \\
\hline & $15 \% \mathrm{ETOH}$ & 14 & $8 / 57$ & $0 / 0$ & $24.8 \pm 1.5$ & $6.7 \pm 2.7$ \\
\hline & $20 \%$ ETOH & 6 & $4 / 66$ & $1 / 17$ & $24.3 \pm 2.2$ & $4.1 \pm 1.6$ \\
\hline
\end{tabular}

* Diet days $1-18$

Rest-special diet days 6-18.

fetal whole body zinc concentrations were not altered by this short period of zinc deficiency. Hurley and Mutch (24) also found that fetal zinc concentrations in fetal rats were not significantly lower after transitory gestational zinc deficiency, even though the offspring were reduced in weight and had a high incidence of congenital malformations. It is not surprising that maternal liver zinc content was not lower in the groups fed a low zinc diet, because maternal tissue levels are resistant to transient periods of zinc deprivation (25). However, maternal plasma zinc levels fall rapidly and transient zinc deficiency is known to be teratogenic (6).

Since the dramatic effect of the combination of the zinc deficiency and alcohol on fetal resorptions and congenital malformations was not due to lower fetal zinc concentrations, we postulate that the mechanism of impaired fetal growth was via interference with protein synthesis and that the teratogenesis was related to impairment of one or more of the 70 zinc metalloenzymes. Alcohol dehydrogenase is a zinc metalloenzyme, and Chernoff (26) has previously demonstrated that fetal abnormalities and maternal blood alcohol levels were inversely related to maternal alcohol dehydrogenase activity. Lower alcohol dehydrogenase activity would cause higher blood alcohols to be delivered to the fetus. To explore further the interrelationship of zinc nutrition in fetal alcohol syndrome, we plan to measure maternal alcohol dehydrogenase levels in relation to zinc intake.

It is clear that the fetal alcohol syndrome is not the result of zinc deficiency alone, because alcohol alone was teratogenic in the high zinc groups. Effects observed included lower fetal weight, open eyelids, and diminished cranial ossification. However, adverse effects were much more severe in the animals given alcohol with insufficient zinc, indicating that zinc deficiency potentiates the teratogenic effects of alcohol. Animal work has shown that supplementary zinc has a beneficial effect on fetal growth by increasing protein synthesis (27). It is possible that nutritional intervention by zinc supplementation to alcoholic women during pregnancy may reduce the incidence or severity of the fetal alcohol syndrome.

Acknowledgments. The authors thank Dr. Donald Parker and Dr. Robert Walls for assistance with statistics, Dr. Donald Frederick for plasma alcohol determinations, Jim Bates and Mamie Perry for technical assistance, and Isabelle Lehman and Charlotte Gaines for typing the manuscript.

\section{REFERENCES}

1. Jones KL, Smith DW, Ulleland CN. Streissgerth AP 1973 Pattern of malformations in offspring of chronic alcoholic women. Lancet 1:1267-1271
2. Smith DW, Jones KL, Hanson JW 1976 Perspectives on the cause and frequency of the fetal alcohol syndrome. Ann NY Acad Sci 273:138-139

3. Clarren SK 1981 Recognition of the fetal alcohol syndrome. JAMA 245:24362439

4. Flynn A, Martier SS, Sokol RJ, Miller SI, Golden NL, Villano BC 1981 Zinc status of pregnant alcoholic women: a determinant of fetal outcome. Lancet $1: 572-575$

5. Gordon EF, Gordon RC, Passal DB 1981 Zinc metabolism: basic, clinical, and behavioral aspects. J Pediatr 99:341-349

6. Hurley LS. Growan J. Swenerton H 1971 Teratogenic effects of short term and transitory zinc deficiency in rats. Teratology 4:199-203

7. Grishan FK. Patwardhan R, Greene HL 1982 Fetal alcohol syndrome: Inhibition of placental transport as a potential mechanism for fetal growth retardation in the rat. J Lab Clin Med 100:45-52

8. Meadows NJ, Smith MF, Keeling PWN, Ruse W, Day J, Scopes JW, Thompson RPH 1981 Zinc and small babies. Lancet 2:1135-1137

9. Hambridge KM, Krebs NJ, Jacobs MA, Favier A, Guyette L. Ikle DN 1983 Zinc nutritional status during pregnancy: a longitudinal study. Am J Clin Nutr 37:429-442

10. Hinkers HJ 1978 The influences of alcohol on the fetus. J Perinat Med 6:3-14

11. Weiner SG 1980 Nutritional considerations in the design of animal models of the fetal alcohol syndrome. Neurobehav Toxicol 2:175-179

12. Chernoff GF 1977 The fetal alcohol syndrome in micc: an animal model. Teratology 15:223-229

13. Kronick JB 1976 Teratogenic effects of ethyl alcohol administered to pregnant mice. Am J Obstet Gynecol 124:676-680

14. Randall CL, Taylor WJ 1979 Prenatal ethanol exposure in mice: Teratogenic effects. Teratology 19:305-312

5. Streissguth AP, Landesman-Dwyer S, Martin JC, Smith DW 1980 Teratogentic effects of alcohol in humans and laboratory animals. Science 209:353-361

16. Jackson AJ, Schumacher HJ 1979 The teratogenic activity of a thalidomide analogus $\mathrm{EM}_{12}$ in rats on a low zinc diet. Teratology 19:341-344

17. National Research Council 1978 Nutrient Requirements of Laboratory Animals. National Research Council, Washington, D.C., pp 41-47

18. Rasmussen BB. Christensen N 1980 Teratogenic effect of maternal alcohol consumption on the mouse fetus. Acta Path Microbiol Scand A88.285-289

19. Cray DD 1962 Modified benzyl alcohol clearing of alizarin-stained specimens without loss of flexibility. Stain Technol 37:124-125

20. Clegg MS. Keen CL, Lonnerdal B, Hurley LS 1981 Influence of ashing technique on the analysis of trace elements in biological samples. II. Dry ashing. Biol Trace Element Res 3:237-244

21. Ruth RE, Goldsmith SK 1981 Interaction between zinc deprivation and acutc ethanol intoxication during pregnancy in rats. J Nutr 111:2034-2038

22. Miller SI, Del Villano BC, Flynn A, Krumhansl M 1983 Intcraction of alcohol and zinc in fetal dysmorphogenesis. Pharmacol Biochem Behav 18:311-315

23. Kline J, Stein Z, Susser M, Warburton D 1980 Drinking during pregnancy and spontaneous abortion. Lancet 2:176-180

24. Hurley LS, Mutch PB 1973 Prenatal and postnatal development after transitory zinc deficiency in rats. J Nutr 103:649-656

25. Hurley LS, Swenerton H 1971 Lack of mobilization of bone and liver zinc under teratogenic conditions of zinc deficiency in rats. J Nutr 101:597-604

26. Chernoff GF 1980 The fetal alcohol syndrome in mice: maternal variables. Teratology 22:71-75

27. Tanaka H, Nakazawa K. Suzuki N. Arima M 1982 Prevention possibility for brain dysfunction in rat with the fetal alcohol syndrome-low zinc status and hypoglycemia. Brain Dev 4:429-438 